\title{
INTERNACIONALIZAÇÃO, RANKINGS E PUBLICAÇÕES EM INGLÊS: A SITUAÇÃO DO BRASIL NA ATUALIDADE
}

KYRIA REBECA FINARDI FELIPE FURTADO GUIMARÃES

\section{RESUMO}

Este artigo tem como objetivo discutir a relação entre a avaliação da pós-graduação e a internacionalização do ensino superior brasileiro. Para tanto, revisam-se os critérios de avaliação dos rankings e o papel das línguas estrangeiras em tais processos. 0 estudo é de cunho bibliográfico documental e discute as tensões/implicações existentes por trás dessas questões que envolvem o ensino superior. De maneira geral, conclui-se que os critérios de avaliação do ensino superior incluídos nos rankings internacionais não são capazes de capturar a realidade no Brasil e, por isso, não beneficiam a avaliação de nossas instituições. Em relação ao papel das línguas estrangeiras no processo de avaliação e internacionalização do ensino superior como um todo, o estudo mostra que o inglês tem um papel-chave e determinante no resultado dessa avaliação.

PALAVRAS-CHAVE AVALIAÇÃO DA PÓS-GRAdUAÇÃO • INTERNACIONALIZAÇÃO • LÍNGUA ESTRANGEIRA • RANKINGS ACADÊMICOS. 


\section{INTERNACIONALIZACIÓN, RANKINGS Y PUBLICACIONES EN INGLÉS: LA SITUACIÓN DE BRASIL EN LA ACTUALIDAD}

RESUMEN

Este artículo tiene el objetivo de discutir la relación entre la evaluación del postgrado y la internacionalización de la educación superior brasileña. Para ello se revisan los criterios de evaluación de los rankings y el papel de los idiomas extranjeros en tales procesos. El estudio es de cuño bibliográfico documental y discute las tensiones/implicaciones existentes detrás de estas cuestiones que envuelven la educación superior. De manera general se concluye que los criterios de evaluación de la educación superior incluidos en los rankings internacionales no son capaces de capturar la realidad en Brasil y por ello no benefician la evaluación de nuestras instituciones. En lo que se refiere al papel de los idiomas extranjeros en el proceso de evaluación e internacionalización de la educación superior como un todo, el estudio muestra que el idioma inglés tiene un papel fundamental y determinante en el resultado de dicha evaluación.

PALABRAS CLAVE EVALUACIÓN DEL POSTGRADO • INTERNACIONALIZACIÓN • IDIOMA EXTRANJERO • RANKINGS ACADÉMICOS.

\section{INTERNATIONALIZATION, RANKINGS AND PUBLICATIONS IN ENGLISH: THE SITUATION OF BRAZIL NOWADAYS}

ABSTRACT

This paper aims to discuss the relationship between the evaluation of graduate courses and the internationalization of Brazilian higher education. To do so, this study reviews the ranking evaluation criteria and the role of foreign language in these processes. This study is bibliographic and documental and discusses the tensions and implications that exist and underpin the evaluation of graduate courses and the internationalization of higher education. In general, this study shows that the criteria for evaluating higher education used in international rankings do not reflect the reality of Brazil and they do not evaluate our institutions favorably. Concerning the role of foreign language in higher education evaluation and internationalization, the study shows that English plays a key and decisive role in this evaluation.

KEYWORDS GRADUATE EDUCATION EVALUATION • INTERNATIONALIZATION • FOREIGN LANGUAGE • ACADEMIC RANKINGS. 


\section{INTRODUÇÃO}

O intuito deste estudo é o de refletir sobre a atual situação do Brasil no que se refere à internacionalização do ensino superior, à avaliação de instituições de ensino superior por meio de rankings e ao papel da língua inglesa nas publicações acadêmicas nesse contexto. Com esse fim, discutem-se os critérios utilizados nos rankings para avaliar as instituições de ensino superior, bem como o papel das línguas estrangeiras (em geral) e do inglês (em particular) e sua relação com o processo de internacionalização e de avaliação da pós-graduação que perpassa o uso do inglês nas produções acadêmicas. A discussão apresentada no artigo se assenta no pressuposto da existência de uma tensão entre a necessidade de se adequar a tendências globais de avaliação/internacionalização do ensino superior, de um lado, e, de outro, certas especificidades do contexto local brasileiro que não são contempladas pelas políticas de avaliação/internacionalização praticadas por países do Norte hegemônico. A fim de oferecer uma arena para a reflexão sobre essa tensão, este trabalho discute a interface entre a internacionalização e a avaliação da 
educação superior, assim como o papel da língua inglesa e dos rankings de avaliação da educação superior, no contexto "glocal" do Brasil hodierno.

\section{INTERNACIONALIZAÇÃO E LÍNGUA INGLESA}

Vários autores (a exemplo de MATTOS, 2011; FINARDI, 2016a, 2016b; FINARDI; PORCINO, 2014) sugerem que a educação tem sido fortemente afetada pelas transformações da sociedade, advindas da globalização e da revolução tecnológica que amplia espaços, tempos e vozes. Uma consequência dessa transformação é a internacionalização do ensino superior, definida como a integração de aspectos ou dimensões internacionais, interculturais ou globais na missão, função ou produto da educação superior (KNIGHT, 2008). Conforme apontado por Menezes de Souza (2015), o processo de internacionalização está tão ligado à globalização que fica difícil saber se a internacionalização é uma consequência da globalização ou agente desta. O autor alerta, ainda, para a cumplicidade estratégica percebida no processo de internacionalização da educação neoliberal, citando como exemplo os programas Ciência sem Fronteiras (CsF) e Idiomas sem Fronteiras (IsF), abordados mais adiante neste estudo.

Cabe destacar que o programa CsF impactou instituições de ensino superior brasileiras ao propor $100 \mathrm{mil}$ bolsas de estudo no exterior, para alunos e pesquisadores, a partir de 2011. Instituições que até então não tinham muita experiência com a mobilidade para o exterior tiveram de se adequar rapidamente às diretrizes desse programa. Todavia, a questão do nível de proficiência em idioma estrangeiro dos estudantes brasileiros não foi considerada nas fases iniciais do programa. Isso resultou numa grande procura, a princípio, por bolsas para Portugal e Espanha, dada a proximidade do idioma de tais países com o português brasileiro. Diante desse contexto, o então programa Inglês sem Fronteiras (IsF-Inglês) foi criado em 2012, para tentar suprir a deficiência de proficiência na língua inglesa. O programa IsF-Inglês foi posteriormente expandido para Idiomas sem Fronteiras (IsF) em 2014, com o intuito de atender à necessidade de
1 Neologismo resultante da fusão dos termos global e local, que se refere à presença da dimensão local na produção de uma cultura global, bem como à influência da cultura global na cultura local 
desenvolvimento de proficiência em outros idiomas estrangeiros, inclusive de português como língua estrangeira (PLE), a fim de subsidiar a internacionalização do ensino superior brasileiro.

Segundo Archanjo (2016), o CsF representa o mais alto investimento já feito pelo governo brasileiro para estimular a mobilidade acadêmica nas áreas tecnológicas. Finardi e Archanjo (no prelo), em um capítulo de livro sobre os impactos dos programas CsF e IsF na internacionalização brasileira, concluem que: 1) apesar de o programa IsF ter sido criado a partir das lacunas detectadas no programa CsF (tais como o baixo nível de proficiência em inglês dos candidatos ao CsF), o programa IsF, ao contrário do CsF, expandiu-se a partir de 2014, tornando-se independente do CsF e sendo possivelmente o programa de internacionalização mais importante do governo brasileiro nos últimos tempos; 2) o CsF é responsável por ter colocado a internacionalização na pauta das universidades brasileiras, principalmente as de pequeno e médio porte, que ainda não pensavam em se internacionalizar antes do CsF; e 3) apesar de o CsF ter sido responsável pela criação de uma "agenda de internacionalização" nas universidades brasileiras, o IsF foi responsável pela consolidação dessa agenda, por meio de ações como as propostas de políticas linguísticas institucionais para a internacionalização.

Nota-se que o momento atual é marcado por uma internacionalização do ensino superior sem precedentes, movida pela globalização, acompanhada por uma revolução nas comunicações e pelas migrações, incluindo a mobilidade acadêmica. Nesse cenário, a possibilidade de se comunicar em outros idiomas é uma competência relevante na superação de barreiras geográficas e/ou linguísticas para o desenvolvimento profissional e/ou acadêmico (FLORY; SOUZA, 2009). Entretanto, é preciso estar atento ao risco potencial dessa internacionalização, tida por muitos como colonizadora (CASTRO-GÓMEZ, 2007), violenta (ANDREOTTI et al., 2015; JORDÃO, 2017) e, possivelmente, enviesada (FINARDI, 2017).

Exemplos da busca por uma maior internacionalização, por meio do uso do inglês, podem ser encontrados em reportagens (“Ensino ministrado em inglês avança em 
universidades do Brasil”, no jornal Folha de São Paulo) $)^{2}$ e em estudos realizados por organismos internacionais, como o British Council, que indicam a oferta de 695 cursos ministrados em inglês em instituições de ensino superior (IES) brasileiras (BRITISH COUNCIL, 2016). Trata-se de iniciativas que têm como objetivos: 1) ampliar a atratividade das IES brasileiras para captar mais acadêmicos estrangeiros; 2) preparar os brasileiros para estudos no exterior; e 3) alcançar melhores notas junto aos órgãos que avaliam o ensino superior. Isso porque o acolhimento de estrangeiros, o envio de brasileiros ao exterior e o número de cursos ministrados em inglês são itens importantes na avaliação do ensino superior e no processo de internacionalização das IES brasileiras. Buscando discutir a relação dos rankings e das línguas estrangeiras com o processo de avaliação da educação brasileira (em geral) e da pós-graduação (em particular), o presente estudo propõe uma reflexão com base na análise desses itens antes de abordar o que pode estar por trás deles e da avaliação do ensino superior brasileiro.

Stein et al. (2016) apontam a necessidade de analisar a internacionalização do ensino superior de forma crítica, considerando as intenções e resultados desse processo, a fim de evitar o risco de que a internacionalização reproduza padrões nocivos de engajamento educacional. A análise dos padrões de engajamento educacional é feita por meio de uma cartografia social, com quatro possibilidades de articulação da internacionalização, que são descritas a seguir.

A primeira articulação, chamada de internacionalização para a economia do conhecimento global (internationalization for a global knowledge economy), entende a educação superior como chave para o sucesso da economia do conhecimento global. Nessa articulação, o ensino superior é considerado vital para o crescimento econômico nacional, bem como para a competitividade global, por meio da produção de pesquisa, invenções e inovações. Certas áreas como ciência, tecnologia, engenharia e matemática (science, technology, engineering and mathematics, ou STEM, na sigla em inglês) são priorizadas em detrimento de outras áreas humanas e sociais. Nessa visão, a mobilidade acadêmica serve para preparar os alunos
2 Disponivel em: <http://wwwl.folha. uol.com.br/educacao/2016/09/1813083ensino-em-ingles-avanca-emuniversidades-do-brasil.shtml>. Acesso em: 14 mar. 2017. 
3 Disponivel em: <http://noticias.ufsc $\mathrm{br} / 2017 / 03 /$ ufsc-participa-de-eventode-apresentacao-do-programa-maisciencia-mais-desenvolvimento/> Acesso em: 14 mar. 2017 para o mercado de trabalho global. É possível ver evidências de tal articulação no programa Ciências sem Fronteiras, que prioriza o envio de acadêmicos dessas áreas no Brasil e que foi recentemente transformado no programa Mais Ciência, Mais Desenvolvimento (MCMD), conforme notícia atual. ${ }^{3}$

Nesse paradigma, o sucesso dos professores é medido por produtos de pesquisa com potencial de gerar receita, por publicações em periódicos internacionais e por colaborações com instituições internacionais bem ranqueadas. Na economia do conhecimento, o PIB (Produto Interno Bruto) é equacionado ao capital de conhecimento, ou seja, países fora do eixo ocidental teriam PIBs menores porque careceriam de capital de conhecimento adequado para aumentar sua produtividade.

Como ilustração dessa visão, Stein et al. (2016) citam o exemplo do projeto "21 Day International Challenge" da Universidade de Canterbury, na Nova Zelândia, que tem como objetivo estimular alunos dessa universidade a criar projetos inovadores para solucionar problemas identificados na comunidade de Tarong, nas Filipinas. O projeto parte do pressuposto de que o capital humano desenvolvido pelos neozelandeses tem utilidade para a comunidade Filipina, num formato paternalístico, com forte apelo etnocentrista de autoafirmação benevolente.

A segunda articulação vê a internacionalização como um bem público (internationalization as a global public good) e enfatiza a importância da democratização do acesso à educação superior em uma escala mundial, assumindo que o público se beneficiará da produção de universidades (especialmente no Norte Global). Nesse caso, a educação superior é vista como vital para a produção de bens públicos como democracia, prosperidade e conhecimento.

Para exemplificar essa articulação, Stein et al. (2016) mencionam a campanha "The world beyond 2015 - Is higher education ready?", lançada pela Association of Commonwealth Universities, para conscientizar como a educação superior pode e deve responder aos desafios além de 2015, numa antecipação dos objetivos de desenvolvimento sustentável das Nações Unidas. A campanha parte do pressuposto de que as 
universidades são as principais produtoras de conhecimento apropriado e relevante para solucionar os desafios atuais de pobreza, (in)sustentabilidade ambiental e epidemias.

Já a terceira articulação, denominada internacionalização antiopressiva (anti-oppressive internationalization), é baseada na noção de solidariedade a favor da mudança sistêmica, para alcançar maior justiça social. Essa articulação problematiza a visão do imaginário domínio global e critica a economia do conhecimento global pelo seu apoio acrítico ao capitalismo. A visão antiopressiva contesta práticas de internacionalização que enfatizam o acesso, exigindo a negação ou despolitização seletiva da diferença e motivando a conformidade com padrões educacionais ou modos de produção de conhecimento do ocidente. Ao fazer isso, tal vertente critica as duas anteriores e questiona a benevolência da educação superior amplamente presumida pela economia do conhecimento global e pela articulação da internacionalização como bem público.

A visão antiopressiva articula-se com visões de justiça social ligadas ao feminismo, anticapitalismo, anticolonialismo, anti-imperialismo e antirracismo. Ela defende os que presumivelmente são prejudicados por programas e políticas de internacionalização como, por exemplo, os programas de voluntariado no exterior que podem explorar ou ser nocivos para as comunidades locais, bem como podem promover um cosmopolitismo elitista e exclusivista. Certos programas desse tipo ajudam a perpetuar visões ocidentais e impedem o questionamento dos estudantes internacionais sobre como suas posições, dentro de uma economia global, podem contribuir para o dano que eles tentam corrigir com suas viagens ao exterior.

Assim, o objetivo dessa articulação seria o de conscientizar os alunos de sua cumplicidade no dano local e global, além de trazer o conhecimento da periferia para o centro, ao invés de exportar o conhecimento do centro para a periferia. Como tal, essa visão é contrária ao universalismo eurocêntrico que subjaz os sistemas de avaliação por meio de ranqueamento de universidades, assim como de políticas educacionais de organizações como o Banco Mundial e a Organização para a Cooperação e Desenvolvimento Econômico (OCDE). 
Para ilustrar essa vertente, os autores descrevem o caso da Universidade Federal da Integração Latino-Americana (UNILA), uma universidade inter-regional criada em 2007 na fronteira entre Argentina, Brasil e Paraguai, como parte do terceiro ciclo de expansão do ensino superior no Brasil. O primeiro ciclo de expansão se concentrou na expansão de acesso, enquanto o segundo ciclo teve como foco a reestruturação de universidades existentes. Diferentemente de outras universidades no Brasil, a UNILA oferece instrução plurilíngue e, ao contrário de outras universidades ocidentais, a UNILA se posiciona contra tendências hegemônicas, uma vez que sua missão não inclui aspirações de liderança, prestígio ou imperativos econômicos. A orientação da UNILA é um bom exemplo de como uma instituição pode repensar os padrões de reprodução de domínio.

Por fim, a quarta articulação, de translocalismo relacional (relational translocalism), é o que Stein et al. (2016) pensam ser possível para a internacionalização dentro da lógica do capitalismo global contemporâneo. Assim como na articulação antiopressiva, há um reconhecimento dos padrões de domínio e do fato de que ciclos de violência são produzidos por meio dessa lógica. Porém, além da crítica a tal lógica, há um compromisso em identificar a cumplicidade de cada um. Essa vertente está desiludida não apenas com o conteúdo, mas também com a forma do imaginário dominante global, reconhecido como sendo insustentável e prejudicial, por proporcionar prosperidade e segurança para alguns, em detrimento de outros que estão sujeitos à austeridade e à violência.

Como exemplo dessa articulação, Stein et al. (2016) citam um programa para estudantes internacionais (basicamente norte-americanos) no Brasil, coordenado por Bill Calhoun, em Fortaleza, para corrigir as origens e efeitos da pobreza existencial. Em sua chegada ao Brasil, os alunos (norte-americanos) são levados para favelas e ficam lá por várias semanas. No primeiro dia, eles têm um choque de realidade ao constatar que suas aspirações de "fazer a diferença" nos problemas brasileiros são efeitos de sua ideologia baseada na separabilidade e proteção de suas vantagens econômicas, 
negando a violência necessária para estabelecer essa vantagem. Nesse programa, a pobreza existencial envolve a redescoberta do sentido de conexão com o corpo de cada um, com forças criativas, com outras pessoas e seres, por meio de práticas estéticas e espirituais e engajamento intelectual crítico. Durante o programa, os alunos são colocados em organizações e movimentos sociais, por curtos períodos de tempo, como parte de uma rede que envolve comunidades indígenas, quilombolas e sem-terra, bem como Organizações Não Governamentais (ONGs) e governos locais. O objetivo do programa é o de estimular a autorreflexão da cumplicidade com estruturas violentas e não sustentáveis de sistemas globais.

Stein et al. (2016) concluem que suas experimentações com cartografias sociais foram motivadas pelo desejo de sair da zona de conforto e da visão da internacionalização do ensino superior que reafirma a benevolência, a redenção, a inocência, em direção a uma visão de novas possibilidades de entendimento que deem conta da complexidade, tensão, dificuldades e paradoxos do tema. Nesse sentido, Finardi (2017) propõe uma visão de internacionalização crítica que consiga questionar os caminhos e interpretações que esse

processo tem tomado no Brasil. Entretanto, essa visão não é consensual, como se observará na revisão de autores favoráveis às práticas atuais de internacionalização, dentre elas, a da avaliação do ensino superior por meio de rankings.

\section{RANKING E AVALIAÇÕES}

Gama e Klagsbrunn (2014) entendem que é possível medir uma instituição por indicadores de qualidade e quantidade tais como os rankings. Os autores afirmam que não é por acaso que a Lei de Diretrizes e Bases da Educação (LDB) brasileira determina o padrão mínimo de qualidade do ensino oferecido pelo Estado (BRASIL, 1996). Essa norma também se aplica ao ensino superior, em que o principal indicador de qualidade é o Índice Geral de Cursos (IGC) (BRASIL, [201-]), que considera a qualidade dos cursos de graduação e pós-graduação. Outro índice de avaliação da qualidade da graduação é o Conceito Preliminar de Curso (CPC), utilizado 
4 Disponivel em: <http://www.capes. gov.br/avaliacao/sobre-a-avaliacao> Acesso em: 15 mar. 2017 para avaliar o desempenho dos alunos no Exame Nacional de Desempenho de Estudantes (Enade).

Em relação à avaliação da pós-graduação, a Coordenação de Aperfeiçoamento de Pessoal de Nível Superior (Capes) é responsável por medir a qualidade dos cursos de pós-graduação para cada área. Segundo informações do site da Capes, ${ }^{4}$ a avaliação do Sistema Nacional de Pós-Graduação foi estabelecida a partir de 1998, sendo orientada pela Diretoria de Avaliação da Capes e realizada com a participação da comunidade acadêmico-científica, por meio de consultores ad hoc. Essa avaliação tem como objetivo certificar a qualidade da pós-graduação brasileira e identificar assimetrias regionais e de áreas estratégicas do conhecimento. Ela é realizada em 49 áreas de avaliação, número vigente em 2017, e segue uma mesma sistemática e conjunto de quesitos básicos estabelecidos pelo Conselho Técnico Científico da Educação Superior (CTC-ES).

A Capes avalia os programas de pós-graduação seguindo uma escala de 1 a 7 , de modo que as notas 1 e 2 descredenciam os cursos, e apenas os programas com nota igual ou superior a 3 podem ser renovados ou propor novos cursos. A nota 3 significa desempenho regular, atendendo ao padrão mínimo de qualidade. A nota 4 é atribuída a um programa com bom desempenho e 5 é a nota indicada para um nível muito bom. As notas 6 e 7 indicam desempenho equivalente ao alto padrão internacional.

Outra medida de avaliação institucional que ganhou popularidade com a internacionalização crescente do ensino superior (e que tem provocado muita discussão e controvérsia em relação ao seu uso) são os rankings universitários. Em sua dissertação sobre o Guia do Estudante, Lourenço (2014) alega que as classificações são incorporadas nas políticas públicas de avaliação, especialmente no que se refere a avaliações em grande escala como, por exemplo, o Enade, com a criação do CPC e do IGC.

Além disso, considerando a avaliação do ensino superior, nota-se que as IES têm atribuído importância ao desenvolvimento de sua reputação internacional, em busca de altos padrões acadêmicos, de maneira a estarem mais bem posicionadas perante as demais instituições com as 
quais competem por recursos e melhores classificações nos rankings.

Essa postura de buscar visibilidade tem motivado as instituições a procurar por "acreditação", isto é, a garantia de qualidade de seus serviços, tanto por organismos nacionais quanto internacionais. Esse desejo por reconhecimento e visibilidade internacional tem estimulado a participação em rankings acadêmicos. Exemplos desses rankings e mecanismos de avaliação são: o Ranking Universitário Folha (RUF), Times Higher Education (THE), SCImago, Journal Citation Reports (JCR), Academic Ranking of World Universities (ARWU - Xangai) e o QS World University Rankings. Todavia, é importante refletir sobre como as instituições, órgãos de controle e agências de acreditação têm atuado (e influenciado) no monitoramento de ações de internacionalização.

De acordo com Lourenço (2014), uma série de críticas foram levantadas contra rankings. Brito $\left(2008^{5}\right.$ apud LOURENÇO, 2014) argumenta que as classificações não são indicadores de boa qualidade, e Dias Sobrinho $\left(2010^{6}\right.$ apud LOURENÇO, 2014) acrescenta que a avaliação das classificações pode ser injusta, uma vez que pode estar baseada em dados errôneos. Lourenço cita outros autores (CALDERÓN; POLTRONIERI; BORGES, $2011^{7}$ apud Lourenço, 2014) que são favoráveis aos rankings porque entendem que eles podem conferir direitos e fornecer informações úteis aos seus usuários. Para esses autores, os rankings são mecanismos adotados pelo Estado para fornecer informações aos cidadãos e, como tais, podem constituir poderosas ferramentas para fortalecer os direitos dos consumidores (CALDERÓN; POLTRONIERI; BORGES, 2010, p. $107^{8}$ apud LOURENÇO, 2014, p. 17).

Essa visão da população acadêmica como "consumidores" e das instituições de ensino como "fornecedoras" não passa despercebida de severas críticas ao sistema neoliberal, que tem buscado, no setor privado, o financiamento para cobrir o rombo deixado com o declínio de financiamento público na educação. Autores como Vavrus e Pekol (2015) chegam a insinuar que a crescente internacionalização do ensino superior é fortemente motivada pela busca por financiamento privado advindo de mensalidades de alunos estrangeiros.
5 BRITO, Marcia Regina Ferreira. O Sinaes e o Enade: da concepção à implantação. Avaliação, Campinas: Sorocaba, SP, v. 13, n. 3, p. 841-850 nov. 2008.

6 DIAS SOBRINHO, José. Qualidade avaliação: do Sinaes a índices. Avaliação, Campinas; Sorocaba, SP, v. 13, n. 3, p. 817-825, mar. 2010.

7 CALDERÓN, Adolfo Ignacio; POLTRONIERI, Heloisa; BORGES, Regilson Maciel. Os rankings na educação superior brasileira: políticas de governo ou de estado? Ensaio: Avaliação de Políticas Públicas em Educação, Rio de Janeiro, v. 19, n. 73 p. 813-826, out./dez. 2011.

8 CALDERÓN, Adolfo Ignacio; POLTRONIERI, Heloisa; BORGES, Regilson Maciel. Avaliação, rankings e qualidade da educação superior. Revista Estudos: ABMES, Brasília, DF, v. 19, n. 39, p. 103-109, dez. 2010. 
No Brasil, pode-se mencionar o estudo de Finardi e Ortiz (2015) que analisou o processo de internacionalização de duas instituições de ensino superior, uma pública federal e outra privada. Os autores partiram de estudos sobre motivação para a internacionalização em instituições de ensino superior do Norte (principalmente da Europa) e que sugeriam que a internacionalização do ensino superior coincidia com o declínio do sistema de financiamento (público) das universidades. Em outras palavras, a motivação para a internacionalização nas universidades no Norte tinha um forte viés de interesse econômico, uma vez que, ao se internacionalizarem, essas universidades poderiam garantir financiamento externo (por meio de mensalidades de alunos estrangeiros).

Com base nessa sugestão, Finardi e Ortiz (2015) investigaram uma universidade pública e outra privada no Brasil, partindo do pressuposto de que a universidade privada (que pode cobrar mensalidades) talvez tivesse uma motivação maior para a internacionalização do que a universidade pública investigada. Contrariamente à hipótese levantada, os dados do estudo mostraram que a universidade pública tinha muito mais interesse na internacionalização do que a privada. Em face desses resultados, os autores concluíram que possivelmente a universidade privada não tem interesse (econômico) na internacionalização, pois o mercado interno no Brasil é bastante confortável para esse tipo de instituição, de tal sorte que elas não precisam buscar financiamento fora (no exterior) quando há tantos "clientes" em potencial aqui mesmo. Segundo dados do Instituto de Estudos e Pesquisas Educacionais Anísio Teixeira (Inep), ${ }^{9}$ pouco mais de três quartos de toda a população universitária brasileira se encontram em universidades privadas enquanto apenas um terço está em públicas.

Em relação às motivações para a internacionalização, Jenkins (2013) classifica as universidades em cinco grupos distintos, dependendo do perfil e motivação para a internacionalização: 1) universidades domésticas - cujo foco está no seu próprio contexto local; 2) universidades imperialistas - que têm uma forte atuação internacional de recrutamento para atrair os estudantes estrangeiros, mas fazem 
relativamente pouco para mudar sua organização, instalações e serviços "em casa"; 3) universidades internacionalmente conscientes - que estão mudando a sua organização e cultura para ter um perfil internacional, mas ainda não estão plenamente comprometidas com o exterior; 4) universidades engajadas internacionalmente - que estão impulsionando uma agenda de internacionalização "em casa", que normalmente inclui avaliação curricular, para oferecer programas de ensino globais incentivando sua equipe a buscar parcerias de pesquisa e de ensino no exterior; 5) universidades focadas internacionalmente - a minoria delas.

Sabe-se que universidades no mundo todo sofrem efeitos da globalização e do declínio do sistema neoliberal, cada uma se adaptando a essa realidade de uma forma diferente. Entretanto, Vavrus e Pekol (2015) alegam que, nessa reestruturação do sistema educacional superior, é possível notar um padrão em que países no Norte se beneficiam mais da globalização e da internacionalização do ensino superior do que países no Sul.

Nesse sentido, Finardi, Santos e Guimarães (2016) reportam dados de 2008 trazidos pela OECD (2010, p. 314 ${ }^{10}$ apud JENKINS, 2013, p. 4), que citam cinco países concentrando a recepção de mais da metade dos estudantes estrangeiros no ensino superior do mundo (EUA 18,7\%, Reino Unido 10\%, Austrália 6,9\%, França 7,3\% e Alemanha 7,3\%), enquanto países anglófonos (EUA, Reino Unido, Austrália, Canadá e Nova Zelândia), em conjunto, representaram quase a metade (43\%).

Assim como Vavrus e Pekol (2015) acreditam que a internacionalização beneficia mais o Norte do que o Sul, Finardi, Santos e Guimarães (2016) sugerem que a globalização e a internacionalização do ensino superior também parecem beneficiar mais os países anglófonos. Os autores se baseiam em dados de Hamel (2013) que mostram viés tendencioso para o inglês nas publicações internacionais. Nesse sentido, Pennycook (1998) alerta sobre os interesses ideológicos por trás da expansão da língua inglesa no mundo, e Rajagopalan (2005) faz o mesmo ao mostrar a geopolítica do inglês e seus reflexos no Brasil.

Todavia, vale ressaltar que as produções acadêmicas são importantes veículos de disseminação e avaliação do ensino
10 ORGANISATION FOR ECONOMIC CO-OPERATION AND DEVELOPMENT. Education at a Glance 2010: OECD Indicators. Paris: OECD, 2010. Disponível em: <http:// www.oecd.org/edu/skills-beyondschool/45926093.pdf>. Acesso em: 15 mar. 2017. 
superior, frequentemente consideradas nos rankings. Finardi e França (2016), em um estudo sobre o papel do inglês na produção e circulação acadêmica nacional da área de Letras, sugerem que ele afeta significativamente a avaliação da produção brasileira. Tanto é que, apesar de o Brasil ter a $13^{\mathrm{a}}$ maior produção acadêmica mundial, essa produção não é bem avaliada (qualitativamente), principalmente devido ao idioma no qual ela é produzida e circula.

Em relação aos efeitos positivos dos rankings, Laus e Magro (2013) defendem que eles têm sido utilizados como modelos de boas práticas para o autodesenvolvimento das instituições, oferecendo certificação de qualidade e intercâmbio de boas práticas para a internacionalização das instituições de ensino superior. Outros efeitos dos rankings são a visibilidade internacional e a concorrência entre as instituições de ensino superior, para serem reconhecidas como universidades de classe mundial.

\section{O BRASIL EM RANKINGS INTERNACIONAIS E NACIONAIS}

Entre os rankings citados anteriormente, um dos mais respeitados é o ARWU - promovido pela Universidade de Xangai, também conhecido como o Ranking de Xangai, e publicado desde 2003 -, e seu equivalente europeu, o THE - publicado anualmente desde 2004. Ambos os rankings avaliam as instituições de ensino superior com base na pesquisa, produtividade, impacto e excelência. O ARWU tem sido muito criticado na Europa, especialmente na França, por causa de seu foco na pesquisa à custa da educação. Nas edições do ARWU de 2009, 2010 e 2012, havia seis universidades brasileiras entre as 500 melhores do mundo (Universidade de São Paulo - USP, Universidade Estadual de Campinas - Unicamp, Universidade Federal de Minas Gerais - UFMG, Universidade Federal do Rio de Janeiro - UFRJ, Universidade Federal de São Paulo - Unifesp, Universidade Federal do Rio Grande do Sul - UFRGS). Entre as 200 melhores, havia apenas uma universidade brasileira (a USP) na $175^{\mathrm{a}}$ posição em 2007, 196 posição em 2008 e nenhuma universidade brasileira em 2009 ou 2010. A USP voltou a figurar nesse ranking em 2012, na $158^{\mathrm{a}}$ posição. 
Conforme o ranking ARWU latino-americano de 2014, a USP perdeu o primeiro lugar na região para a Universidade Católica do Chile, cuja produção científica em colaboração com cientistas estrangeiros foi maior que a da USP. Segundo Gama e Klagsbrunn (2014), uma das razões pelas quais a USP não está na lista das 200 melhores universidades é a falta de cursos ministrados em inglês (English Medium Instruction ou EMI, na abreviação em inglês). Em relação ao uso do EMI no Brasil, Martinez (2016) afirma que pouquíssimas universidades tinham esse tipo de curso antes de 2010.

De acordo com o mesmo levantamento divulgado em Gama e Klagsbrunn (2014), as instituições de ensino superior brasileiras têm dez universidades entre as vinte maiores na América Latina: USP, Unicamp, UFRJ, Universidade Estadual Paulista "Júlio de Mesquita Filho" (Unesp), UFMG, UFRGS, Pontifícia Universidade Católica do Rio de Janeiro (PUC-RJ), Unifesp, Universidade de Brasília (UnB) e Universidade Federal de São Carlos (UFSCar). Dessas, apenas a USP, Unesp e PUC-RJ oferecem cursos EMI em nível de graduação. Gama e Klagsbrunn (2014) afirmam que as universidades brasileiras têm bons resultados em "número de trabalhos por membro da faculdade", mas não em "citações", sugerindo que os brasileiros estão atuando melhor em termos de quantidade do que de qualidade. Conforme aventado por Finardi e França (2016), a avaliação da "qualidade" pode ser afetada pela língua de publicação e, como a produção acadêmica brasileira ainda é publicada majoritariamente em português, ela circula principalmente nos núcleos lusofalantes.

Em relação aos rankings brasileiros, um dos mais conhecidos é o Ranking Universitário da Folha (RUF), publicado pelo jornal Folha de S. Paulo, que compara 192 universidades brasileiras e trinta cursos de graduação no país, avaliados em cinco dimensões: ensino, integração com o mercado de trabalho, pesquisa, internacionalização e inovação. A avaliação de internacionalização considera as publicações internacionais por professor indexadas no sistema Web of Science, bem como a proporção de professores estrangeiros nas universidades brasileiras.

De acordo com Laus e Magro (2013), a crescente importância atribuída aos rankings, juntamente com os numerosos 
debates que eles criaram, levou o Centro Europeu de Ensino Superior (Unesco-Cepes) e o Instituto de Políticas de Ensino Superior de Washington a criarem um grupo de especialistas em rankings internacionais - o International Ranking Expert Group (IREG). Na segunda reunião realizada pelo grupo em 2006 em Berlim, o IREG concordou em considerar dezesseis princípios para a análise dos rankings em relação aos seguintes itens: a) os propósitos e objetivos dos sistemas de classificação; b) a metodologia - a concepção e o peso dos indicadores; c) a coleta e tratamento de dados; e d) a apresentação dos resultados.

No que diz respeito aos objetivos dos sistemas de classificação, o IREG sugere que a classificação não deve ser a única forma de avaliação das IES. As classificações internacionais devem também ter em conta as características regionais das IES, reconhecendo que os conceitos de qualidade podem não ser partilhados por diferentes instituições. Em se tratando da metodologia, o IREG recomenda o uso de dados auditados e verificáveis sempre que possível, o que inclui aqueles coletados de acordo com procedimentos certificados para coleta de dados, aumentando a credibilidade da classificação, como o uso de conselhos consultivos. Com relação à apresentação dos resultados, o IREG indica o fornecimento de informações claras sobre todos os fatores utilizados para desenvolver uma tabela de classificação, permitindo aos usuários escolher como a classificação é exibida. Os rankings devem ser compilados para eliminar ou reduzir erros nos dados originais, sendo organizados ou publicados em um formato que permita ao compilador fazer correções, se necessário, para que os usuários estejam cientes disso.

Os "Princípios de Berlim", como vieram a ser conhecidos, foram adotados em um modelo de classificação multidimensional, que considera os papéis que as universidades desempenham na sociedade e no sistema educacional em que operam. É possível concluir que os rankings exigem um investimento substancial de recursos de instituições de ensino superior e, como sugerido por Finardi, Santos e Guimarães (2016), parecem ter sido concebidos por e para universidades de língua inglesa ou por aqueles que adotaram cursos EMI em seus currículos. 
Laus e Magro (2013) sugerem que comparar universidades brasileiras com universidades americanas e europeias não beneficia as IES brasileiras e, portanto, escolheram o Ranking de Instituições SCImago (SCImago Institutions Rankings, ou SIR), que mede o número de publicações e mostra o Brasil na $14^{\mathrm{a}}$ posição entre os países com a mais alta produção científica, com 34.145 publicações em 2008 na Scopus, uma das maiores bases de dados científicos. Esse ranking coloca o Brasil atrás de países desenvolvidos como os EUA $\left(1^{\circ}\right)$, Inglaterra $\left(3^{\circ}\right)$, Alemanha $\left(4^{\circ}\right)$ e Japão $\left(5^{\circ}\right)$, mas também o coloca entre os principais países em desenvolvimento e do BRICS, ${ }^{11}$ como a China $\left(2^{\circ}\right)$ e Rússia $\left(15^{\circ}\right)$. Ainda de acordo com Laus e Magro (2013), esses números fornecem uma dimensão de avaliação muito diferente das IES brasileiras em relação aos rankings, pois mostra que, apesar de o Brasil ter apenas cerca de 650 pesquisadores para cada um milhão de habitantes, o número de artigos científicos publicados por brasileiros representa 54\% do total publicado na América Latina e $2,63 \%$ no mundo.

Da mesma forma que o ARWU e o THE, o SCImago também possui rankings regionais como o Ranking Ibero-Americano de Produção Científica Internacional, cujos indicadores incluem a produção científica, medida pelo número de publicações, e a colaboração internacional, medida por publicações em conjunto com outros países. Também avalia a qualidade científica média, medida pelo impacto científico de uma instituição, e a percentagem de artigos publicados nas revistas mais influentes do mundo, medida pela quantidade e origem das citações recebidas. De acordo com esse ranking, Espanha e Brasil lideram a produção científica, quando se considera o conjunto de países ibero-americanos, e as universidades espanholas e brasileiras figuram entre as dez mais produtivas, com cinco instituições espanholas, quatro brasileiras e uma mexicana na lista.

Em relação à cooperação internacional, que aumenta a visibilidade e o impacto científico das instituições e, portanto, sua internacionalização, destacam-se as universidades espanholas e portuguesas, sendo que no Brasil a UFRJ é a mais internacionalizada das três primeiras posições nesse ranking
$11 \mathrm{Na}$ área de Economia, o termo BRICS se refere aos países com economias emergentes que formam um grupo de cooperação, composto por Brasil, Rússia, Índia, China e África do Sul. 
no Brasil. Em termos de qualidade das publicações (quesito afetado pela língua de publicação), prevalecem o espanhol e o português. Esses idiomas, apesar de difundidos na América Latina, estão num contexto em que $89 \%$ das instituições têm valores de citação abaixo da média mundial. Além disso, apenas cinco das 109 instituições dessa região foram avaliadas com qualidade científica média acima da média mundial.

\section{INTERNACIONALIZAÇÃO, PUBLICAÇÕES EM INGLÊS E O DOCUMENTO DE ÁREA DE LETRAS E LINGUÍSTICA}

Em relação à língua de publicação, e conforme sugerido anteriormente por Finardi e França (2016) e por Hamel (2013), a publicação em inglês aumenta a possibilidade de receber citações e, consequentemente, de ter impacto internacional. Isso cria um círculo vicioso no qual os países que mais publicam em inglês têm cada vez mais impacto na produção científica internacional, atraindo assim mais recursos e acadêmicos internacionais.

Considerando-se o papel das línguas estrangeiras (em geral) e do inglês (em particular) na avaliação da pós-graduação e da internacionalização do ensino superior brasileiro, de acordo com Gimenez (2013), os brasileiros querem falar inglês fluentemente, mas apenas cerca de 5\% deles o fazem. Finardi, Prebianca e Momm (2013) alegam que o inglês é necessário para expandir o acesso à informação, e Finardi e Tyler (2015) acrescentam que ele também é necessário para garantir acesso à educação on-line por meio de cursos abertos e dirigidos a um público amplo (Massive Online Open Courses, ou MOOCs, na abreviação em inglês). Finardi (2014) sugere que o inglês deve ser ensinado como uma língua internacional (e obrigatória) nas escolas brasileiras para lutar contra o fosso social criado pela oferta de cursos de línguas particulares, disponíveis apenas a uma pequena (e privilegiada) parte da população que pode pagar por eles. A Medida Provisória (MP) n. 746, proposta em 2016 e convertida na Lei n. 13.415/2017 (BRASIL, 2017), que trouxe uma reformulação no ensino médio, parece ir nessa direção, com a indicação da obrigatoriedade do ensino do inglês e de mais um idioma estrangeiro, dependendo da 
disponibilidade de recursos de cada instituição. Dessa forma, haveria a possibilidade de os alunos ingressarem no ensino superior com melhores condições de disputar oportunidades propiciadas pela internacionalização das universidades, tais como ofertas de mobilidade estudantil para o exterior semelhantes ao programa Ciência sem Fronteiras.

Esse programa, criado em 2011 e “congelado” em 2014, está sendo substituído pelo programa Mais Ciência, Mais Desenvolvimento. Acredita-se que essa nova proposta focará principalmente a pós-graduação, diferentemente da primeira edição do CsF, que teve como ênfase o envio de estudantes brasileiros em nível de graduação. Outra mudança trazida pelo MCMD é a escolha de universidades de renome e prestígio internacional, que podem exigir certo nível de proficiência linguística na língua de instrução, razão pela qual acredita-se que as línguas estrangeiras terão um papel ainda mais importante no programa MCMD e no processo de internacionalização como um todo. Entretanto, conforme lembra Menezes de Souza (2015), já citado neste artigo, programas como o CsF, IsF e MCMD podem representar uma cumplicidade estratégica com o processo de internacionalização, que, segundo Andreotti et al. (2015) e Jordão (2017), é provável que imponha violências ou, ainda, de acordo com Castro-Gómez (2007), um processo de colonização.

As constantes avaliações realizadas pelos órgãos governamentais, já mencionadas, que acompanham o estabelecimento e desenvolvimento de cursos de educação superior têm incluído itens que contemplam aspectos de internacionalização. O Documento de Área de Letras e Linguística (DA-LL), ${ }^{12}$ elaborado no âmbito do Ministério da Educação (MEC), por meio de sua Coordenação de Aperfeiçoamento de Pessoal de Nível Superior e sua Diretoria de Avaliação, exibe uma seção (seção IV) dedicada ao tema da internacionalização, denominada "considerações e definições sobre internacionalização/ inserção internacional”.

Nele consta a seguinte visão da área de Letras e Linguística sobre a internacionalização:

A área de Letras e Linguística considera que sua internacionalização tem por finalidade a cooperação com
12 Disponivel em: <http://www. capes.gov.br/images/documentos/ Documentos_de_area_2017/41_LETR_ docarea_2016.pdf $>$. Acesso em: 14 mar. 2017. 
instituições e centros de pesquisa no exterior, em um patamar de paridade e de reciprocidade. Em outras palavras, a pós-graduação brasileira na Área deve participar internacionalmente na produção de conhecimento, dando contribuição efetiva nessa produção e, ao mesmo tempo, obtendo ganhos de qualidade nos diálogos entre pares. (BRASIL, 2016, p. 26)

Esse documento ainda menciona que a Área de Letras e Linguística se encontra em estágio adiantado de inserção internacional, fruto de esforços iniciados nos anos 1980, principalmente nos programas avaliados com nota 6 e 7, de acordo com os critérios da Capes. Apesar disso, Finardi e França (2016), ao analisarem essa área, identificaram que um dos maiores entraves para a expansão da internacionalização ainda é a questão da língua de publicação, já que essa área publica sua produção principalmente em português, idioma que tem alcance restrito no mundo acadêmico, se comparado ao inglês.

Para alcançar tais notas, os programas são avaliados de modo a identificar se conseguem atingir os níveis de excelência acadêmica semelhantes aos centros internacionais de destaque, na formação de recursos humanos. Também são avaliadas maneiras inovadoras de se fazer pesquisa e a capacidade de atrair professores, pesquisadores e alunos estrangeiros.

Sendo assim, o DA-LL apresenta propostas para a internacionalização dos programas, de forma que possam ser mais bem avaliados nesse aspecto. Tais propostas incluem: 1) ações iniciais de cooperação internacional do programa [de pós-graduação]; e 2) ações iniciais de acolhimento de professores, pesquisadores e alunos de instituições estrangeiras no programa [de pós-graduação]. Também são propostas ações avançadas, que serão tratadas mais adiante.

Ao avaliar as ações iniciais de cooperação, o DA-LL procura identificar se os docentes realizaram estágio de pós-doutorado no exterior e se participaram de eventos científicos no exterior, com apresentações de trabalhos e publicações em anais. Também visa a identificar se os discentes realizaram doutorado sanduíche no exterior e se participaram de eventos científicos, com apresentações de trabalhos. 
Em se tratando da avaliação do acolhimento de estrangeiros, o DA-LL busca identificar se houve esse acolhimento de professores e pesquisadores estrangeiros para ministrar disciplinas ou conferências, ou mesmo recebimento de estrangeiros para participar de eventos científicos organizados por programa de pós-graduação no Brasil. De maneira similar, procura identificar se foram acolhidos e/ou matriculados no Brasil alunos estrangeiros para disciplinas, estágios, cursos ou eventos científicos. Além disso, avalia-se também se a página (site) do programa de pós-graduação está disponível em mais de um idioma.

O DA-LL ainda apresenta propostas mais avançadas para a internacionalização dos programas de pós-graduação, tais como: a) participação em projetos de pesquisa conectados a grupos de pesquisa estrangeiros; b) busca de financiamento de agências de fomento internacionais; c) atuação como professor ou pesquisador visitante em instituições estrangeiras; d) realização de estágios de pesquisa em instituições estrangeiras; e) publicações acadêmicas (livros, artigos, capítulos, etc.) em âmbito internacional; f) organização de eventos no exterior ou eventos internacionais no Brasil; g) participação em associações científicas internacionais; h) participação em comitês editoriais de periódicos estrangeiros; e i) atuação em bancas de avaliação no exterior.

Quanto ao acolhimento de professores e alunos estrangeiros, o DA-LL aponta outras propostas avançadas, como: a) recebimento de professor estrangeiro para ministrar disciplina ou orientar pesquisa; b) recebimento de alunos em regime de dupla titulação ou cotutela; c) oferta de disciplinas em outros idiomas; d) publicação em periódicos estrangeiros ou nacionais que aceitem textos em idioma estrangeiro; e e) realização de eventos por teleconferência, de forma a aproximar acadêmicos de diferentes partes do globo. Já os requisitos para a Apresentação de Propostas de Cursos Novos (APCN) ${ }^{13}$ da Capes exigem que as propostas de cursos novos contenham informações sobre a projeção internacional dos docentes. 13 Disponivel em: <http://www. capes.gov.br/images/documentos/ Criterios_apcn_2semestre/Criterios de_APCN_2017_-_Letras.pdf>. Acesso em: 14 mar. 2017. Também é necessário informar se os docentes participam de redes internacionais de pesquisadores. 


\section{CONSIDERAÇÕES FINAIS}

Tendo em vista o papel das línguas estrangeiras no processo de internacionalização e avaliação do ensino superior, bem como a baixa correlação entre a quantidade da produção acadêmica nacional e sua qualidade (medida por meio do impacto gerado por essa produção, influenciada pelo idioma de publicação), este estudo conclui que a baixa proficiência em línguas estrangeiras, e particularmente em inglês, é um sério entrave ao desenvolvimento da internacionalização do ensino superior brasileiro. Essa questão é corroborada por Finardi e Archanjo (2015) e pela criação e manutenção, mesmo durante a crise econômica que tem assolado o país desde 2014, do programa nacional Idiomas sem Fronteiras, com foco especial para os investimentos feitos no inglês, por meio do programa Inglês sem Fronteiras. A repaginação do maior programa de mobilidade acadêmica brasileiro, o CsF - que, em sua nova roupagem como MCMD, terá ênfase na pós-graduação -, também reforça esse ponto, já que possivelmente exigirá que os candidatos ao programa tenham maior conhecimento prévio de línguas estrangeiras.

Em relação ao papel dos rankings na avaliação da educação superior como um todo, e da pós-graduação em especial, este estudo conclui que os rankings internacionais são propostos com um viés que beneficia os países do Norte e aqueles que falam ou ensinam inglês como segunda língua. Nesse sentido, apesar de representarem importantes medidas de qualidade do ensino superior, é necessário ter cautela ao usar rankings internacionais para capturar a realidade nacional. Uma alternativa é a de continuar trabalhando na proposta/adequação de rankings nacionais, sem deixar de observar as tendências de avaliação dos rankings internacionais. Uma boa solução seria a de adotar critérios próprios para a avaliação de universidades dos países do Sul, realizando uma compensação/ponderação de pontos em relação a países dessa região, ao incluir esses dados nos rankings internacionais. 


\section{REFERÊNCIAS}

ANDREOTTI, Vanessa de Oliveira et al. Mapping interpretations of decolonization in the context of higher education. Decolonization: Indigeneity, Education \& Society, v. 4, n. 1, p. 21-40, 2015.

ARCHANJO, Renata. Moving globally to transform locally? Academic mobility and language policy in Brazil. Language Policy, v. 16, n. 3, p. 1-22, 2016.

BRASIL. Lei n. 9.394, de 20 de dezembro de 1996. Estabelece as Diretrizes e Bases da Educação Nacional. Brasília, DF, 1996. Disponível em: <http://www. planalto.gov.br/ccivil_03/leis/L9394.htm>. Acesso em: 14 mar. 2017.

BRASIL. Lei 13.415, de 16 de fevereiro de 2017. Altera as Leis nos 9.394, de 20 de dezembro de 1996, que estabelece as diretrizes e bases da educação nacional, e 11.494, de 20 de junho 2007, que regulamenta o Fundo de Manutenção e Desenvolvimento da Educação Básica e de Valorização dos Profissionais da Educação, a Consolidação das Leis do Trabalho - CLT, aprovada pelo DecretoLei no 5.452 , de $1^{\circ}$ de maio de 1943 , e o Decreto-Lei ${ }^{\circ} 236$, de 28 de fevereiro de 1967; revoga a Lei $n^{\circ} 11.161$, de 5 de agosto de 2005; e institui a Política de Fomento à Implementação de Escolas de Ensino Médio em Tempo Integral. Brasília, DF: Casa Civil, 2017. Disponível em: <http://www.planalto.gov.br/ ccivil_03/_ato2015-2018/2017/lei/L13415.htm>. Acesso em: 14 mar. 2017.

BRASIL. Instituto Nacional de Estudos e Pesquisas Educacionais Anísio Teixeira. Índice Geral de Cursos 2011. [201-]. Disponível em: < http://portal.inep. gov.br/indice-geral-de-cursos-igc->. Acesso em: 14 mar. 2017.

BRASIL. Ministério da Educação. Coordenação de Aperfeiçoamento de Pessoal de Nível Superior. Diretoria de Avaliação. Documento de área: Letras e Linguística. Brasília, DF: MEC/Capes/DA, 2016.

BRITISH COUNCIL. Guide of Brazilian Higher Education Courses in English 2016. Disponível em: < https://www.britishcouncil.org/sites/default/files/guide_ brazilian_highered_courses_inenglish_limpo_indexado_2.pdf>.

Acesso em: 14 mar. 2017.

CASTRO-GÓMEZ, Santiago. Decolonizar la universidad. La hybris del punto cero y el diálogo de saberes. In: CASTRO-GÓMEZ, Santiago; GROSFOGUEL, Ramón (Org.). El giro decolonial. Reflexiones para una diversidad epistémica más allá del capitalismo global. Bogotá: Siglo del Hombre Editores, 2007. p. 79-91.

FINARDI, Kyria Rebeca. The slaughter of Kachru's five sacred cows in Brazil: Affordances of the use of English as an international language. Studies in English Language Teaching, v. 2, p. 401-411, 2014.

FINARDI, Kyria Rebeca. Language policies and internationalisation in Brazil: The role(s) of English as an additional language. In: SCIRIHA, Lydia (Org.). International perspectives on bilingualism. Newcastle upon Tyne: Cambridge Scholars Publishing, 2016a. p. 79-90. v. 1.

FINARDI, Kyria Rebeca. Globalization and English in Brazil. In: FINARDI, Kyria Rebeca (Org.). English in Brazil: views, policies and programs. Londrina: Eduel, 2016b. p. 15-36. v. 1. 
FINARDI, Kyria Rebeca. Internacionalização crítica: possibilidades para a inclusão e (in)formação superior. A educação docente em contextos de internacionalização/mundialização. In: JORNADA INTERNACIONAL DE LINGUÍSTICA APLICADA CRÍTICA: A linguística aplicada crítica e seu compromisso com a sociedade, 1., 24 e 25 abr. 2017, Brasília, DF. Anais... Brasília, DF: Universidade de Brasília, 2017. Mesa-redonda.

FINARDI, Kyria Rebeca; ARCHANJO, Renata. Reflections of internationalization of education in Brazil. In: INTERNATIONAL BUSINESS AND EDUCATION CONFERENCE, 2015, Nova Iorque. 2015 Proceedings... Nova Iorque: Clute Institute, 2015. p. 504-510. v. 1.

FINARDI, Kyria Rebeca; ARCHANJO, Renata. Washback effects of the Science without Borders, English without Borders and Language without Borders programs in Brazilian language policies and rights. In: SIINER, Maarja; HULT, Francis M.; KUPISCH, Tanja (Org). Bridging language acquisition and language policy. Dordrecht: The Netherlands. (Springer Language Policy Book). No prelo.

FINARDI, Kyria Rebeca; FRANÇA, Claudio. O inglês na internacionalização da produção científica brasileira: evidências da subárea de Linguagem e Linguística. Intersecções, Jundiaí, ed. 19, ano 9, n. 2, p. 234-250, maio. 2016.

FINARDI, Kyria Rebeca; ORTIZ, Ramón Andrés. Globalization, internationalization and education: what is the connection? International E-Journal of Advances in Education, v. 1, p. 18-25, 2015.

FINARDI, Kyria Rebeca; PORCINO, Maria Carolina da Silva. Tecnologia e metodologia no ensino de inglês: impactos da globalização e da internacionalização. Tha do Desterro, Florianópolis, n. 66, p. 239-282, 2014.

FINARDI, Kyria Rebeca; PREBIANCA, Gicele Vergine; MOMM, Christiane Fabiola. Tecnologia na educação: o caso da internet e do inglês como linguagens de inclusão. Cadernos do IL, Porto Alegre, n. 46, p. 193-208, 2013.

FINARDI, Kyria Rebeca; SANTOS, Jane Meri; GUIMARÃES, Felipe Furtado. A relação entre línguas estrangeiras e o processo de internacionalização: evidências da coordenação de letramento internacional de uma universidade federal. Interfaces Brasil/Canadá, Pelotas, v. 16, n. 1, p. 233-255, 2016.

FINARDI, Kyria Rebeca; TYLER, Jhamille. The role of English and technology in the internationalization of education: insights from the analysis of MOOCs. In: INTERNATIONAL CONFERENCE ON EDUCATION AND NEW LEARNING TECHNOLOGIES, 2015, Barcelona. Proceedings... Barcelona: IATED/ EduLearn 15, 2015. p. 11-18.

FLORY, Elizabete Villibor; SOUZA, Maria Thereza Costa Coelho de. Bilinguismo: diferentes definições, diversas implicações. Revista Intercâmbio, São Paulo, v. 19, p. 23-40, 2009.

GAMA, Zacarias; KLAGSBRUNN, Victor Hugo. Avaliação institucional: rankings, quantidade, qualidade, epistemologia e ontologia. Repositório UFSC, Florianópolis, 2014. Disponível em: <https://repositorio.ufsc.br/xmlui/ handle/123456789/131474>. Acesso em: 14 mar. 2017. 
GIMENEZ, Telma. A ausência de políticas para o ensino da língua inglesa nos anos iniciais de escolarização no Brasil. In: NICOLAIDES, Christine; SILVA, Kleber Aparecido; TILIO, Rogerio; ROCHA, Claudia Hilsdorf (Org.). Política e políticas linguísticas. Campinas, SP: Pontes, 2013. p. 401-411.

HAMEL, Rainer. L'anglais, langue unique pour les sciences? Le rôle des modèles plurilingues dans la recherche, la communication scientifique et l'enseignement supérieur. Synergies Europe, n. 8, p. 53-66, 2013.

JENKINS, Jennifer. English as a lingua franca in the international university: The politics of academic English language policy. London: Routledge, 2013.

JORDÃO, Clarissa Menezes. Decolonizing Brazilian language teacher education. JORNADA INTERNACIONAL DE LINGUÍSTICA APLICADA CRÍTICA: A LINGUÍSTICA APLICADA CRÍTICA E SEU COMPROMISSO COM A SOCIEDADE, 1., 2017, Brasília, DF. Anais... Brasília, DF: Universidade de Brasília, 24 e 25 abr. 2017. A educação docente em contextos de internacionalização/mundialização: Mesa-redonda.

KNIGHT, Jane. Higher Education in turmoil: the changing world of internationalization. 2008. Disponível em: <https://www.sensepublishers. com/media/475-higher-education-in-turmoil.pdf>. Acesso em: 21 mar. 2017.

LAUS, Sonia Pereira; MAGRO, Dalva. Os rankings acadêmicos internacionais: gênese e relevância. Repositório UFSC, Florianópolis, 2013. Disponível em: <https://repositorio.ufsc.br/handle/123456789/113139>. Acesso em: 14 mar. 2017.

LOURENÇO, Henrique da Silva. Os rankings do Guia do Estudante na educação superior brasileira: um estudo sobre as estratégias de divulgação adotadas pelas instituições que obtiveram o prêmio melhores universidades. 2014. 205 f. Dissertação (Mestrado em Educação) - Pontifícia Universidade Católica de Campinas, Campinas, SP.

MARTINEZ, Ron. English as a Medium of Instruction (EMI) in Brazilian higher education: challenges and opportunities. In: FINARDI, Kyria Rebeca (Org.). English in Brazil: views, policies and programs. Londrina: Eduel, 2016. p. 191-228.

MATTOS, Andrea Machado de Almeida. Novos letramentos, ensino de língua estrangeira e o papel da escola pública no século XXI. Revista X, Curitiba, v. 1, p. 33-47, 2011.

MENEZES DE SOUZA, Lynn Mario. Políticas de internacionalização na educação superior: questões e caminhos. In: INTERNATIONAL CONGRESS OF CRITICAL APPLIED LINGUISTICS: LANGUAGE, ACTION, AND TRANSFORMATION, out. 2015, Brasília, DF. Anais... Brasília, DF: ICCAL, 2015. p. 19-21.

PENNYCOOK, Alastair. English and the discourses of colonialism. London: Routledge, 1998.

RAJAGOPALAN, Kanavillil. A geopolítica da língua inglesa e seus reflexos no Brasil: por uma política prudente e propositiva. In: LACOSTE, Yves; RAJAGOPALAN, Kanavillil (Org.). A Geopolítica do Inglês. São Paulo: Parábola, 2005. p. 135-159. 
STEIN, Sharon; ANDREOTTI, Vanessa; BRUCE, Judy; SUŠA, Rene. Towards different conversations about the internationalization of higher education. Comparative and International Education / Éducation Comparée et Internationale, v. 45, n. 1, 2016. Disponível em: <http://ir.lib.uwo.ca/cie-eci/vol45/iss1/2>. Acesso em: 20 maio 2017.

VAVRUS, Frances; PEKOL, Amy. Critical internationalization: moving from theory to practice. FIRE: Forum For International Research in Education, v. 2 , n. 2, p. 2, 2015. Disponível em: < http://preserve.lehigh.edu/cgi/viewcontent. cgi?article=1036\&context=fire $>$. Acesso em: 14 mar. 2017.

KYRIA REBECA FINARDI

Professora do Departamento de Linguagens, Cultura e Educação (DLCE) e dos Programas de Pós-Graduação em Educação (PPGE) e Linguística (PPGEL) da Universidade Federal do Espírito Santo (UFES), Vitória, Espírito Santo, Brasil

kyria.finardi@gmail.com

\section{FELIPE FURTADO GUIMARÃES}

Doutorando do Programa de Pós-Graduação em Linguística (PPGEL) da Universidade Federal do Espírito Santo (UFES), Vitória, Espírito Santo, Brasil felipeguim2@yahoo.com.br 
